\title{
Unveiling aerosol-cloud interactions - Part 1: Cloud contamination in satellite products enhances the aerosol indirect forcing estimate
}

\author{
Matthew W. Christensen ${ }^{1,2}$, David Neubauer ${ }^{3}$, Caroline A. Poulsen ${ }^{1}$, Gareth E. Thomas ${ }^{1}$, Gregory R. McGarragh ${ }^{2}$, \\ Adam C. Povey ${ }^{4}$, Simon R. Proud ${ }^{2}$, and Roy G. Grainger ${ }^{4}$ \\ ${ }^{1}$ RAL Space, STFC Rutherford Appleton Laboratory, Harwell, OX11 0QX, UK \\ ${ }^{2}$ Atmospheric, Oceanic and Planetary Physics, University of Oxford, Oxford, OX1 3PU, UK \\ ${ }^{3}$ Institute for Atmospheric and Climate Science, ETH Zurich, Zurich, 8092, Switzerland \\ ${ }^{4}$ National Centre for Earth Observation, University of Oxford, Oxford, OX1 3PU, UK
}

Correspondence to: Matthew W. Christensen (matthew.christensen@physics.ox.ac.uk)

Received: 12 May 2017 - Discussion started: 19 May 2017

Revised: 8 September 2017 - Accepted: 12 September 2017 - Published: 7 November 2017

\begin{abstract}
Increased concentrations of aerosol can enhance the albedo of warm low-level cloud. Accurately quantifying this relationship from space is challenging due in part to contamination of aerosol statistics near clouds. Aerosol retrievals near clouds can be influenced by stray cloud particles in areas assumed to be cloud-free, particle swelling by humidification, shadows and enhanced scattering into the aerosol field from (3-D radiative transfer) clouds. To screen for this contamination we have developed a new cloudaerosol pairing algorithm (CAPA) to link cloud observations to the nearest aerosol retrieval within the satellite image. The distance between each aerosol retrieval and nearest cloud is also computed in CAPA.

Results from two independent satellite imagers, the Advanced Along-Track Scanning Radiometer (AATSR) and Moderate Resolution Imaging Spectroradiometer (MODIS), show a marked reduction in the strength of the intrinsic aerosol indirect radiative forcing when selecting aerosol pairs that are located farther away from the clouds $(-0.28 \pm$ $0.26 \mathrm{~W} \mathrm{~m}^{-2}$ ) compared to those including pairs that are within $15 \mathrm{~km}$ of the nearest cloud $\left(-0.49 \pm 0.18 \mathrm{~W} \mathrm{~m}^{-2}\right)$. The larger aerosol optical depths in closer proximity to cloud artificially enhance the relationship between aerosol-loading, cloud albedo, and cloud fraction. These results suggest that previous satellite-based radiative forcing estimates represented in key climate reports may be exaggerated due to the inclusion of retrieval artefacts in the aerosol located near clouds.
\end{abstract}

\section{Introduction}

Aerosols are hypothesised to cool the climate system due to their ability to enhance the reflection of clouds (Twomey, 1974; Albrecht, 1989), particularly ubiquitous warm-phase clouds located in the boundary layer (Christensen et al., 2016a). The uncertainty attached to this cooling effect is considered to be very large (IPCC, 2013) in both satellite and general circulation model (GCM) estimates. The fundamental issues causing this large uncertainty stem from a myriad of challenges related to retrieval artefacts in satellite products (e.g. cloud contamination and 3-D radiative effects) and missing processes in GCMs (e.g. parameterisation schemes related to cloud-top entrainment feedbacks and buffering in aerosol-cloud interactions as discussed in Stevens and Feingold, 2009). Satellite observations suggest that the aerosol indirect radiative cooling effect is about half that of GCMbased estimates (e.g. see Fig. 7.19 in chap. 7 of the IPCC 5th Assessment Report, IPCC, 2013). For future climate projections it is critical to close the satellite-GCM gap in the forcing estimate so we can understand to what extent anthropogenic aerosols may have cooled, and continue to cool, the climate system.

Despite the advances in satellite-based retrievals in recent decades, obtaining robust statistical relationships between aerosols and clouds remains difficult. Challenges associated with obtaining accurate passive satellite retrievals generally involve the following issues: (1) an artificially high aerosol optical depth (AOD) retrieval due to the presence of undetected cloud in areas assumed to be cloud-free (cloud 
contamination) (Remer et al., 2005); (2) radiation scattered by clouds that illuminate the aerosol field and are not accounted for in the 1-D radiative transfer model in satellite retrievals causing erroneously high AOD retrievals (3D effects) (Varnái and Marshak, 2009), and (3) humidification causing aerosols to swell near clouds, thereby enhancing AOD without any increase in aerosol number concentration (humidification effect) (Twohy et al., 2009). Attributing the contribution of these mechanisms to the enhancement in AOD and particle size near clouds is difficult using passive sensing instruments from satellite-based observations alone.

Recent assessments characterising near-cloud aerosol retrieval artefacts were examined using space-borne lidar (Várnai et al., 2013) and ground-based lidar (Ten Hoeve and Augustine, 2016) observations. In general, the Moderate Resolution Imaging Spectroradiometer (MODIS) aerosol products show enhanced aerosol optical depth and particle size several kilometres beyond the cloud edge (Várnai and Marshak, 2015). Evidence from selected Surface Radiation Budget Network (SURFRAD) observations reported in Ten Hoeve and Augustine (2016) suggest that near-cloud contamination in the satellite retrieval can enhance the aerosol cloud cover fraction relationship by approximately $40 \%$ (i.e. cloud cover fraction is larger for the same aerosol optical depth when cloud contaminated pixels are used in the analysis). In addition, the direct aerosol radiative effect (i.e. the increase in reflected radiation due to aerosol loading in clear-sky conditions) in satellite observations is significantly larger (35$65 \%$ ) than that inferred from larger (greater than $20 \mathrm{~km}^{2}$ ) cloud-free ocean regions where the aerosol retrievals are located farther from the clouds (Twohy et al., 2009). The extent to which these near-cloud aerosols influence the correlationbased statistics used as diagnostics for aerosol-cloud interactions in satellite observations is largely unknown at the global scale. The quantification of their impacts on the aerosol radiative forcing estimate is the goal of this study.

Besides the errors in the satellite retrieval, attributing causal relationships between non-collocated cloud and aerosol retrievals is challenging. Passive sensors cannot currently retrieve aerosol and cloud simultaneously, because the imager pixels are classified as being either "cloud" or "cloudfree". To solve the collocation problem a pre-averaging methodology is commonly used (e.g. Sekiguchi et al., 2003; Quaas et al., 2008; Lebsock et al., 2008; Grandey and Stier, 2010; Chen et al., 2014; Gryspeerdt et al., 2016; Christensen et al., 2016a). Typically, the aerosol and cloud properties are pre-averaged over broad regions as a means to encapsulate both retrieval types within a (level-3-type) grid box. The aerosol and cloud bins are typically constructed at a spatial scale of $1^{\circ} \times 1^{\circ}$ at daily time intervals. This method limits the number of sampling pairs to at most 90 (for a 3-month period) from which seasonal regression statistics can be derived. Some studies have also used a back-trajectory model to pair aerosols and clouds (Bréon et al., 2002) and compute aerosol cloud diagnostics using the assumption that the aerosol properties remain constant over the coarse of the trajectory. A disadvantage to using these approaches is if the artefacts in the pixel-scale retrieved data (i.e. the level-2 data) near clouds are not properly screened, the aerosol-cloud relationships may be biased regardless of the methodology used to combine the observations from satellite data.

Another, less common method of collocating aerosols and clouds is data assimilation. This process uses aerosol properties that are extracted from reanalysis products at the location of the observed cloud (Bellouin et al., 2013; Amiri-Farahani et al., 2017). However, the aerosols simulated by the models may be strongly affected by wet deposition (Gryspeerdt et al., 2015), particularly in locations where the satellite observations cannot provide a constraint on the aerosol loading in cloudy areas (Christensen et al., 2016a).

In this paper, we have developed a new collocation method, defined here as the high-resolution cloud-aerosol pairing algorithm (CAPA). In this method high-resolution pixel-scale cloud observations are paired to the nearest aerosol retrieval within the satellite image. These pairs are then aggregated over $1^{\circ} \times 1^{\circ}$ regions. This results in a significant boost to the total number of samples used in the regression statistics from about 90 (using $1^{\circ} \times 1^{\circ}$ pre-averaged daily statistics) to approximately $11 \times 10^{5}$ using CAPA over a 3-month period. In addition, the distance between cloud and aerosol retrievals can be adjusted in CAPA as a means to screen for aerosols next to clouds. This method provides the ability to expose biases in the aerosol-cloud radiative forcing estimate due to satellite artefacts in the retrievals of aerosols near-cloud.

The paper is organised into the following format: satellite data sets and their corresponding retrieval algorithms are described in Sect. 2, the procedure to compute aerosol indirect radiative forcing is in Sect. 3, CAPA is described in Sect. 4, compositing techniques are described in Sect. 5, the results using this approach are compared to the standard preaveraging method as described in Sect. 6, and the summary and discussion of this work and how it relates to our companion paper (Neubauer et al., 2017) are described in Sect. 7.

\section{Satellite data}

Two passive sensors with similar equator crossing times (approximately 10:30 am local), the Advanced Along-Track Scanning Radiometer (AATSR) on Envisat and MODIS on Terra, are used in this study. AATSR is a dual-view instrument having a footprint resolution of about $1 \mathrm{~km}$ at the surface. The two views (satellite zenith angles at $\sim 55^{\circ}$ forward and nadir) offered by the instrument provide nearsimultaneous (within $90 \mathrm{~s}$ ) observations of the same location on the Earth. This provides the ability to separate the surface from the atmospheric signals in order to increase the accuracy of the $1 \mathrm{~km}$ aerosol retrieval (in version 4.01 the aerosol is reported at $1 \mathrm{~km}$ resolution) using the Optimal Retrieval of 
Aerosol and Cloud (ORAC) algorithm (Thomas et al., 2009). Cloud properties are also retrieved using the same inputs (e.g. the cloud mask, surface reflectance data over the ocean, basis for the optimal estimation scheme in the radiative transfer model, and thermodynamic profiles) as the aerosol retrieval algorithm. By using the same inputs for the ORAC forward model we achieve a high degree of consistency between the aerosol and cloud products. This consistency is essential for constraining the complexity in attributing cause and effect in aerosol-cloud interaction studies. The ORAC algorithm for cloud is described in Poulsen et al. (2012) and most recent improvements to the forward model code in Sus et al. (2017) and McGarragh et al. (2017). The high-resolution pixel-scale data are currently available through the European Space Agency (ESA) Climate Change Initiative (CCI) although the aerosol products are averaged to a spatial resolution of $10 \mathrm{~km}$ to be consistent with other satellite products of this kind. The pre-averaged gridded daily products (L3C) used in this study are also available via http://cci.esa.int.

Shortwave and longwave broadband radiative fluxes are obtained using the CC4CL (Community Cloud Retrieval for Climate) algorithm (Christensen et al., 2016b). The code uses the BUGSrad radiative transfer model (Stephens et al., 2001) in conjunction with the input cloud and aerosol properties derived from ORAC. BUGSrad is based on the two-stream approximation and correlated-k distribution methods of atmospheric radiative transfer. It is applied to a single-column atmosphere for which the cloud and aerosol layers are assumed to be plane-parallel. Cloud and aerosol properties retrieved using ORAC are ingested into BUGSrad to compute both shortwave and longwave radiative fluxes for the top and bottom of the atmosphere. The algorithm uses 18 bands that span the electromagnetic spectrum to compute the broadband flux -6 in the shortwave and 12 in the longwave. BUGSrad shows good agreement with the Clouds and the Earth's Radiant Energy System (CERES) observations (Henderson et al., 2013) and has been used to assess the Earth's energy budget using CloudSat observations (Stephens et al., 2012).

The MODIS $1 \mathrm{~km}$ pixel-scale data are obtained from the Terra satellite. Terra was selected for comparison, because it has a similar orbit and equator crossing time as Envisat. To obtain top of atmosphere (TOA) radiative fluxes from MODIS on Terra we ingest the standard collection 6 cloud (MOD06; Platnick et al., 2017) and aerosol (MOD04; Levy et al., 2013) products into the CC4CL radiative flux BUGSrad model. Because the MOD04 product is sampled at $10 \mathrm{~km}$ spatial resolution the data have been resampled at $1 \mathrm{~km}$ resolution to match the cloud product. The ESA CCI projects evaluated products; among them were the standard collection 6 MODIS aerosol and cloud products. ORAC was also applied to MODIS data (within Cloud_cci) and the MODIS-ORAC product was found to agree very well with the MODIS standard products (Hollmann, 2017).

This analysis uses 10 years of AATSR observations spanning from 2002 to 2012. Pixels are screened to include only low-level (cloud top pressure greater than $500 \mathrm{hPa}$ ) liquidphase (cloud top temperature greater than $273 \mathrm{~K}$ ) maritime clouds. Due to limitations in data storage we are only able process 3 months (June, July, and August; JJA) using highresolution MODIS-ORAC (broadband fluxes derived using standard MODIS products) Terra retrievals for comparison.

\section{Aerosol indirect radiative forcing calculation}

Computation of the aerosol indirect radiative forcing estimate is based on a top-down approach in which a systemwide variable, the cloud radiative effect (CRE), is used to compute the radiative forcing as a function of the aerosol loading. This reduces the number of free parameters to just a few (e.g. cloud fraction, cloud albedo, and aerosol index) in which the observational uncertainties are better known (Feingold et al., 2016) compared to other quantities that are difficult to retrieve from passive satellite measurements (e.g. droplet number concentration, cloud condensation nuclei, and cloud thickness). The derivation of the shortwave component of the aerosol indirect radiative forcing at the top of the atmosphere is the same as that used in Chen et al. (2014) and is derived from the cloud radiative effect equation written here as

$F_{\mathrm{CRE}}=F_{\text {clr }}-F_{\text {all-sky }}$,

where $F_{\mathrm{clr}}$ is the clear-sky net radiative flux (i.e. $F_{\mathrm{clr}}=$ $F_{\mathrm{clr}}^{\uparrow}-F_{\mathrm{clr}}^{\downarrow}$, arrows denote the upwelling and downwelling fluxes, respectively) for atmospheric columns in containing no clouds and $F_{\text {all-sky }}$ is the net flux that is observed for allsky conditions (excluding ice clouds here) computed from clear- and cloudy-sky $1 \mathrm{~km}$ pixels located within each $1^{\circ} \times 1^{\circ}$ region. The thermodynamic profiles used in the broadband flux calculations are interpolated to each $1 \mathrm{~km}$ imager pixel from the N256 spatial resolution of the ECMWF (European Centre for Medium range Weather Forecasting) interim reanalysis product. Assuming a relatively dark ocean surface Eq. (1) can be decomposed into

$F_{\text {all-sky }}=\left(1-c_{\mathrm{f}}\right) F_{\text {clr }}+c_{\mathrm{f}} F_{\text {cld }}$,

where $F_{\text {cld }}$ is the component of the radiative flux contributed by clouds and $c_{\mathrm{f}}$ is the cloud cover fraction over the observed area. Combining Eqs. (1) and (2) and considering the shortwave component of the upwelling fluxes, the cloud radiative effect becomes

$F_{\mathrm{CRE}}=c_{\mathrm{f}}\left(A_{\mathrm{clr}}-A_{\mathrm{cld}}\right) F^{\downarrow}$,

where $A_{\text {clr }}$ is the clear-sky albedo, $A_{\text {cld }}$ is the albedo of the cloud and $F^{\downarrow}$ is the daily-mean incoming top of atmosphere solar radiation. Taking the derivative of Eq. (3) with respect to the aerosol index (AI) gives the column TOA cloud radiative effect aerosol sensitivity

$\frac{\mathrm{d} F_{\mathrm{CRE}}^{\mathrm{sW}}}{\mathrm{d} \ln \mathrm{AI}}=\left(\overline{c_{m}}\left[\frac{\mathrm{d} A_{\mathrm{clr}}}{\mathrm{d} \ln \mathrm{AI}}-\frac{\mathrm{d} A_{\mathrm{cld}}}{\mathrm{d} \ln \mathrm{AI}}\right]+\overline{\left(A_{\mathrm{clr}}-A_{\mathrm{cld}}\right)} \frac{\mathrm{d} c_{\mathrm{f}}}{\mathrm{d} \ln \mathrm{AI}}\right) F^{\downarrow}$, 
where $\overline{c_{m}}$ is the climatology of clouds having cloud top pressure greater than $500 \mathrm{hPa}$ and composed of liquid-phase droplets over ocean regions. The derivative terms represent the change in clear-sky and cloudy-sky albedo as a function of aerosol index. The first term on the right-hand side of Eq. (4) is called the intrinsic aerosol effect and includes the impact of aerosol on changes in cloud albedo. The second term is the extrinsic effect, which represents the impact of aerosol on cloud fraction. For further details regarding the derivation of these terms see Chen et al. (2014).

We use aerosol index $\left(\mathrm{AI}=\tau_{\mathrm{a}} \times \AA\right.$, where $\tau_{\mathrm{a}}$ is the aerosol optical depth at $550 \mathrm{~nm}$ and $\AA$ is the Angström exponent derived from the optical depths at 550 and $869 \mathrm{~nm}$ ), because AI has been shown to serve as a better indicator of the column cloud condensation nuclei compared to aerosol optical depth (Nakajima et al., 2001; Gryspeerdt et al., 2017). To limit co-variation between the annual cloud and aerosol cycles with the incoming solar radiation flux, the aerosol-cloud sensitivities are computed, first over each season separately and then combined to form the annual mean aerosol indirect effect sensitivity.

Finally, the aerosol indirect forcing estimate is obtained by multiplying Eq. (4) by an amount of aerosol attributable to anthropogenic activities as determined by MACC-II reanalysis data (i.e. $\Delta \tau_{\mathrm{a}}^{\mathrm{MACC}}=\ln \left(\tau_{\mathrm{a}}^{\mathrm{MACC}}\right)-\ln \left(\tau_{\mathrm{a}}^{\mathrm{MACC}}-\tau_{\mathrm{anth}}^{\mathrm{MACC}}\right)=$ $\ln \left(\frac{1}{1-F_{\text {anth }}}\right)$, where $\tau_{\text {anth }}^{\mathrm{MACC}}$ is the aerosol optical depth attributed to anthropogenic activities). In this calculation we assumed that the fractional change in the anthropogenic AOD is equivalent to the fractional change in anthropogenic AI. This assumption may lead to an underestimation of the aerosol indirect forcing, especially in regions where dust dominates (Gryspeerdt et al., 2016). MACC-II is a satellite-model hybrid data set that utilises the state-of-theart ECMWF-IFS (Integrated Forecast System) aerosol transport model along with a surface emissions inventory and assimilated MODIS data to provide aerosol optical depth for a variety of species including dust, organic carbon, sea-salt, black carbon, and sulfate (e.g. see Morcrette et al., 2009 and Benedetti et al., 2009 for details). Global distributions of the anthropogenic aerosol fraction are provided in Chen et al. (2014) and Bellouin et al. (2013); the global oceanic mean value is about $21 \%$.

\section{Cloud-aerosol pairing algorithm (CAPA)}

The basic approach of CAPA is to pair each cloud observation to the nearest aerosol retrieval. This process is performed within the satellite image (the swath width is $2330 \mathrm{~km}$ for MODIS and $512 \mathrm{~km}$ for AATSR). Distances using Euclidian geometry in pixel-coordinates are computed between each cloud pixel and all possible aerosol retrievals. Given the large number of pixels within the swath this task is computationally demanding if proper screening is not carried out initially. To decrease computation time and the number of possible pairs (for a given cloud observation), the satellite image is divided into sections and pixels are grouped together (typically $250 \times 250$ pixel regions). For pixels near the edge of each square region (within $125 \mathrm{~km}$ ), the search radius is extended to the nearest adjacent square region. These steps eliminate aerosol-cloud pairs at distances greater than approximately $150 \mathrm{~km}$ (for $1 \mathrm{~km}$ pixel-scale data), but potential pairs beyond this length scale occur at low frequencies and are probably less relevant since the cloud-aerosol interaction is less likely to be influenced by the same air mass (Anderson et al., 2003).

In the next step the cloud fraction is computed (using the satellite retrieval cloud mask at $1 \mathrm{~km}$ resolution) as a metric to determine the appropriate search algorithm to use for the given subsection of the satellite granule. If the cloud fraction is high $\left(c_{\mathrm{f}}>50 \%\right)$ then fewer aerosol retrievals exist and the distance between each cloud pixel and all aerosol pixels is computed simultaneously via brute force within that region of the satellite orbit. However, if the cloud fraction is low $\left(c_{\mathrm{f}}<50 \%\right)$ the number of aerosol targets will be larger and the former approach will run much more slowly. In this case the pixels that are adjacent to the cloud observation are searched first (as there is a relatively high probability an aerosol is located in an adjacent pixel when the cloud fraction is lower). If an aerosol retrieval is not found in the adjacent pixels this step is repeated again until an aerosol target is found. By using the search algorithms together (based on cloud fraction) the computation speed decreases by more than $50 \%$ compared to running the retrieval in brute-force mode alone. Finally, if two (or more) aerosol pixels are located at the same distance from the cloud observation then one of them is selected at random. The CAPA run time is approximately $2-6 \mathrm{~min}$ using a single core Intel/AMD at $\sim 3 \mathrm{GHz}$ processor for a typical MODIS granule that contains 2.5 million $1 \mathrm{~km}$ pixels.

The results of CAPA are applied to part of an AATSR orbit and displayed in Fig. 1. The image shows a belt of clouds across the middle of the granule with aerosols retrieved on both sides (Fig. 1b). The cloud-belt is approximately $300 \mathrm{~km}$ wide (Fig. 1c). Aerosols in the lower half of the image have lower optical depths and tend to be located at greater distances to the nearest cloud (green pixels), whereas the aerosols in the upper half of the image are retrieved mostly in a broken cloud field in which the aerosols are located close to the clouds (red pixels). The aerosol retrievals have a "blocky" appearance, because the standard level-2 aerosol products from MODIS (MOD04) and AATSR (V4.02) are averaged over larger $10 \mathrm{~km}^{2}$ pixels. In order to match the cloud and aerosol products and form aerosol-cloud pairs (on the same imager pixel grid), the aerosol products for AATSR and MODIS are resampled at $1 \mathrm{~km}$ resolution.

Aerosol statistics are examined as a function of distance to the nearest cloud in Fig. 2. The observations are comprised of 3 months (JJA in 2008) of data collected across four different $10^{\circ} \times 10^{\circ}$ regions (off the coasts of California, Peru, the Azores, and Namibia). In every region, the mean aerosol op- 

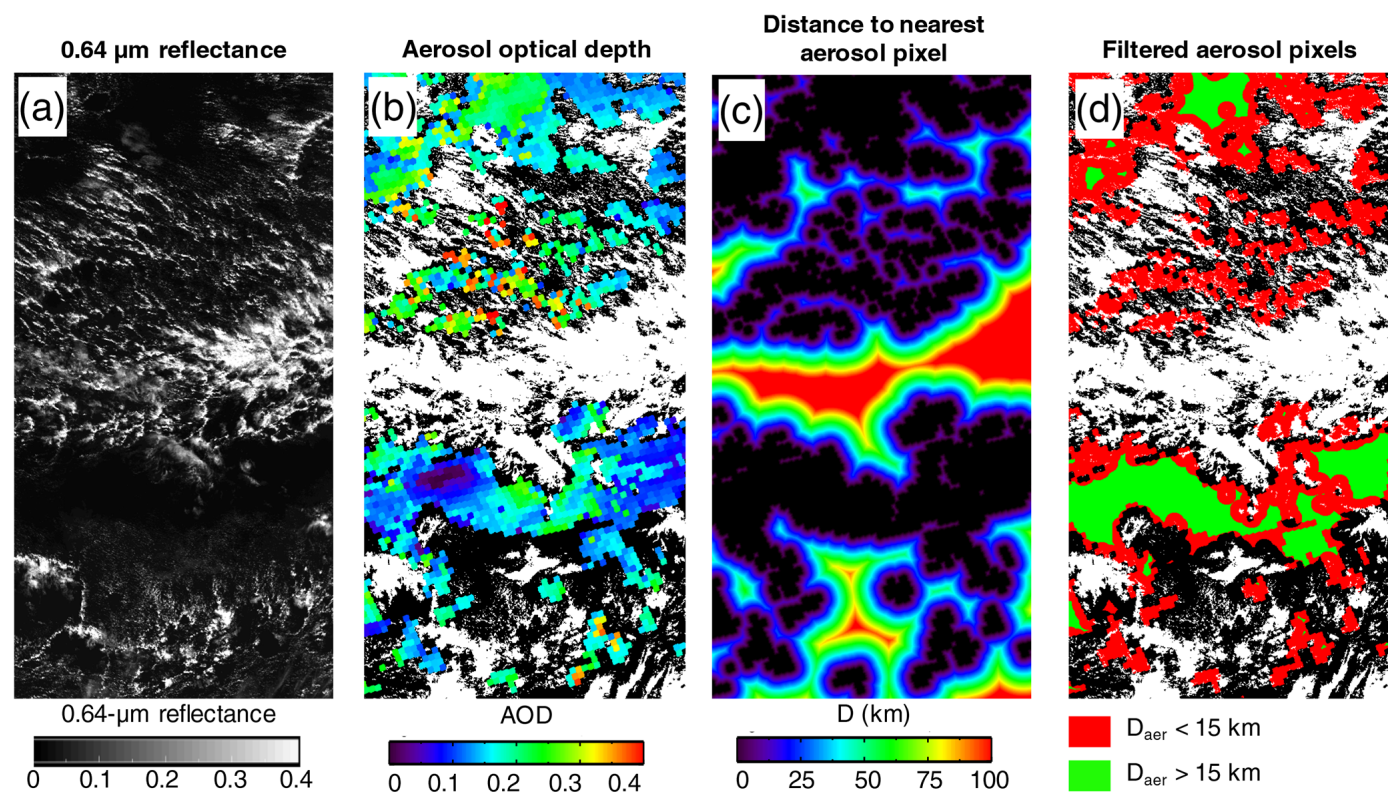

Figure 1. (a) Satellite image of the visible reflectance at $0.64 \mu \mathrm{m}$ from part of an AATSR orbit $\left(512 \times 1000 \mathrm{~km}^{2}\right)$ on the $20 \mathrm{June} 2008$ over the ocean off the west coast of Africa. (b) Coinciding cloud mask (white) and aerosol optical depth (rainbow) retrieved using ORAC and (c) distance from each pixel to the nearest aerosol retrieval. (d) Aerosol retrievals that are located within $15 \mathrm{~km}$ of a cloud are considered contaminated (red), while those farther away than this are considered valid (green).

tical depth increases, the Ångström exponent decreases and the aerosol index increases as the observations are closer in distance to the nearest cloud. In agreement with previous studies we find that about half of all clear-sky columns occur within 4-5 km of the low-level cloud (Várnai and Marshak, 2012). As a consequence, near-cloud aerosols (that are potentially affected by retrieval artefacts) in pre-averaged aerosol data sets would provide substantial weight for the aerosol statistics.

Despite efforts to limit contamination in standard MODIS collection 6 retrievals, threshold values for the darkest and brightest $25 \%$ of pixels in each cluster (Remer et al., 2005) are applied. One complication with the standard MODIS products is that the cloud and aerosol products use different cloud masks to perform their retrievals. Nevertheless, large aerosol optical depths remain in the MODIS-observed pixels near cloud edges, due primarily to 3-D effects (Varnái and Marshak, 2009) and the swelling of aerosols by higher relative humidity. Currently, no effort is made to remove nearcloud pixels from the AATSR ORAC gridded products. This is evident from the faster and less pronounced decrease in aerosol optical depth and Ångström exponent with distance from the nearest cloud in the MODIS product. At distances greater than $15 \mathrm{~km}$ the aerosol optical properties tend to be fairly constant. Similarly, Varnái and Marshak (2009) also noted that beyond $15 \mathrm{~km}$ contamination effects were minimised in MODIS data. Therefore aerosol-cloud relationships are also examined for pairs beyond the $15 \mathrm{~km}$ length scale.

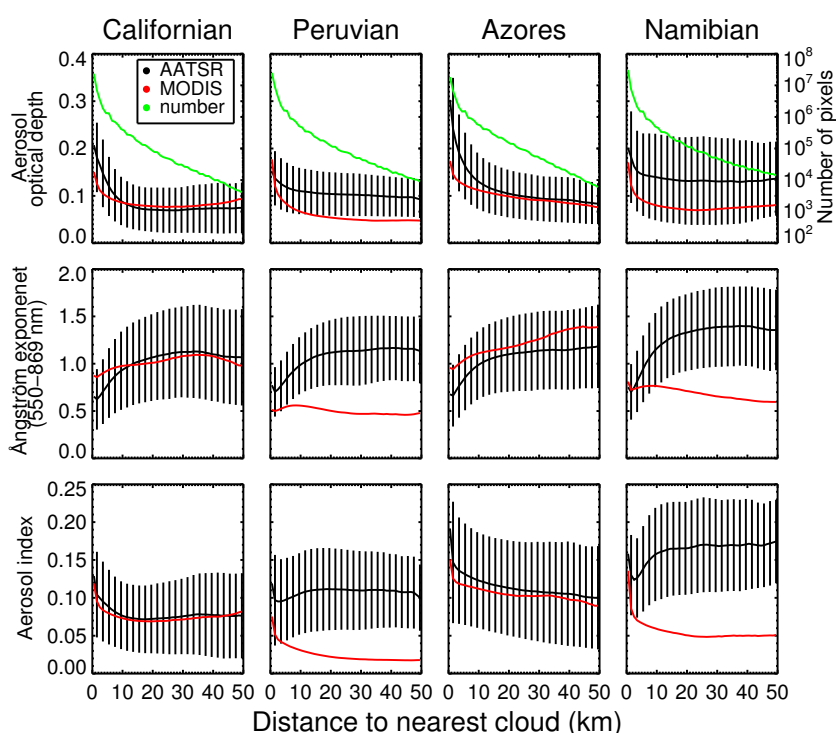

Figure 2. Mean aerosol optical depth as a function of the distance to the nearest cloud mask averaged over $1 \mathrm{~km}$ width bins. Relationships are plotted using AATSR-ORAC (black) and collection 6 MOD04 applied to MODIS-ORAC (red) for JJA 2008 data grouped into $10^{\circ} \times 10^{\circ}$ regions off the coasts of California $\left(20-30^{\circ} \mathrm{N}, 140\right.$ $\left.130^{\circ} \mathrm{W}\right)$, Peru $\left(10-20^{\circ} \mathrm{S}, 80-90^{\circ} \mathrm{W}\right)$, the Azores $\left(15-25^{\circ} \mathrm{N}, 25-\right.$ $\left.35^{\circ} \mathrm{W}\right)$, and Namibia $\left(10-20^{\circ} \mathrm{S}, 0-10^{\circ} \mathrm{E}\right)$. The number of AATSR pixels in each bin are plotted over the results (green). Error bars are denoted by the 1 standard deviation computed over the collection of AATSR retrievals within the bin. 
Table 1. Summary of composites used in this study

\begin{tabular}{ll}
\hline Composite & Description \\
\hline $\begin{array}{l}\text { Nearest high-resolution cloud-aerosol pair } \\
\text { (CAPA-L2) }\end{array}$ & $\begin{array}{l}\text { Comprised of level-2 individual pairs of pixels in which the length scale be- } \\
\text { tween the cloud and nearest high-resolution aerosol retrieval can range from } \\
0 \text { to } 150 \mathrm{~km} \text {. An example of the pixel selection for these cases is displayed in } \\
\text { Fig. } 1 \mathrm{~d} \text {; red and green pixels. }\end{array}$ \\
\hline $\begin{array}{l}\text { Nearest high-resolution cloud-aerosol pair separated } \\
\text { by at least 15 } \mathrm{km} \\
\text { (CAPA-L2_15km) }\end{array}$ & $\begin{array}{l}\text { Same as above except the nearest high-resolution aerosol retrieval has to be } \\
\text { located at least } 15 \mathrm{~km} \text { from any other cloud and cannot exceed a pairing length } \\
\text { scale beyond } 150 \mathrm{~km} \text {. An example of the pixel selection for these cases is } \\
\text { displayed in Fig. 1d; red pixels. }\end{array}$ \\
\hline $\begin{array}{l}\text { Pre-averaged cloud and aerosol } \\
\text { (PRE_AVG-L3) }\end{array}$ & $\begin{array}{l}\text { Pairs are based on uncolocated level-3 pre-averaged } 1^{\circ} \times 1^{\circ} \text { cloud and aerosol } \\
\text { observations from standard MODIS (i.e. MOD08) and AATSR products. }\end{array}$ \\
\hline $\begin{array}{l}\text { Pre-averaged cloud and corrected aerosol } \\
\text { (PRE_AVG-L3_Corr.) }\end{array}$ & $\begin{array}{l}\text { Same as above except the cloud observations are paired to a new aerosol data } \\
\text { set based on pre-averaging only those aerosol pixels that are located at least } \\
15 \mathrm{~km} \text { away from cloud. }\end{array}$ \\
\hline
\end{tabular}

\section{Data stratification}

Results are based on four distinct composites of the data (listed in Table 1). Each composite contains aerosol and cloud pairs which are aggregated into $1^{\circ} \times 1^{\circ}$ regions so that regression statistics can be computed on the basis of the linear least-squares slope between the cloud albedo and the aerosol index. This process is also carried out separately for pixels designated as "cloud-free" in order to derive the clearsky albedo change as a function of aerosol loading (i.e. $\frac{\mathrm{d} A_{\mathrm{cll}}}{\mathrm{d} \ln \mathrm{AI}}$ ) in Eq. (4). Two distinct methodological frameworks are used: (1) the high-resolution CAPA and (2) the low-resolution preaveraging methods.

CAPA is run using two distinct length scales: (1) clouds are paired with the nearest located aerosol (CAPA-L2) and with the nearest aerosol that is located at least $15 \mathrm{~km}$ away from any other cloud (CAPA-L2_15km). The median distance between aerosol and cloud pairs from these two composites is 8.2 and $27.1 \mathrm{~km}$, respectively, thereby providing the ability to screen for aerosol next to cloud. Another advantage of CAPA is that it retains individual L2 pixels, i.e. full-resolution data, for quantifying aerosol-cloud relationships over each $1^{\circ}$ grid box, allowing for more of the aerosol field to be sampled and thus providing more degrees of freedom with which to derive seasonal statistics. For example, the average number of high-resolution samples going into a typical $1^{\circ}$ region over a 3-month period is approximately $3.0 \times 10^{5}$, although the actual number of degrees of freedom is much smaller (each region provides on average about 10 degrees of freedom per day providing roughly 1000 over a 3-month period) owing to oversampling the same aerosol used to make cloud-aerosol pairs. Nevertheless, the typical number of samples in the CAPA composites far exceed those that can be achieved using the standard pre-averaged products (PRE_AVG-L3 and PRE_AVG-L3_Corr.) where at most they provide 90 samples (providing one aerosol-cloud pair sample per day for a given grid box) in a 3-month period. As pointed out later, the reduced sampling in the PRE_AVGL3 composite results in a larger $1 \sigma$ standard error regression error estimate.

\section{Results}

Aerosol-cloud relationships are examined using the CAPA and pre-average methods at a variety of spatio-temporal scales. An assessment of CAPA is carried out at both the regional scale $\left(10^{\circ} \times 10^{\circ}\right)$ in selected locations with predominately low-level clouds (i.e. off the coasts of California, Peru, the Azores, and Namibia) and at the global scale.

\subsection{Global distributions}

The intrinsic aerosol-cloud radiative effect is predominately influenced by the change in cloud albedo as a function of the aerosol index (i.e. $\frac{\mathrm{d} A_{\text {cld }}}{\mathrm{d} \ln \mathrm{Al}}$ ). The regression is quantified using a range of temporal averaging periods using AATSR observations in Fig. 3. As more years of observations are included in the regression the global distribution becomes less noisy (as represented by a decrease in the standard deviation of the regional-scale spatial distribution from $\sigma=0.05$ to 0.02 for the PRE_AVG-L3 composite). However, beyond 5 years the differences in the intrinsic effect between consecutive years become statistically insignificant. We conclude that 10 years of AATSR observations are more than adequate to construct these diagnostics. Regarding MODIS, we acknowledge that the limited 3-month time period may bias the standard error of the regression slope. Therefore, it is used primarily to test the new CAPA method.

Figure 4 shows the global distribution of the observed intrinsic aerosol indirect radiative forcing estimate using AATSR observations. Consistent with Chen et al. (2014), 


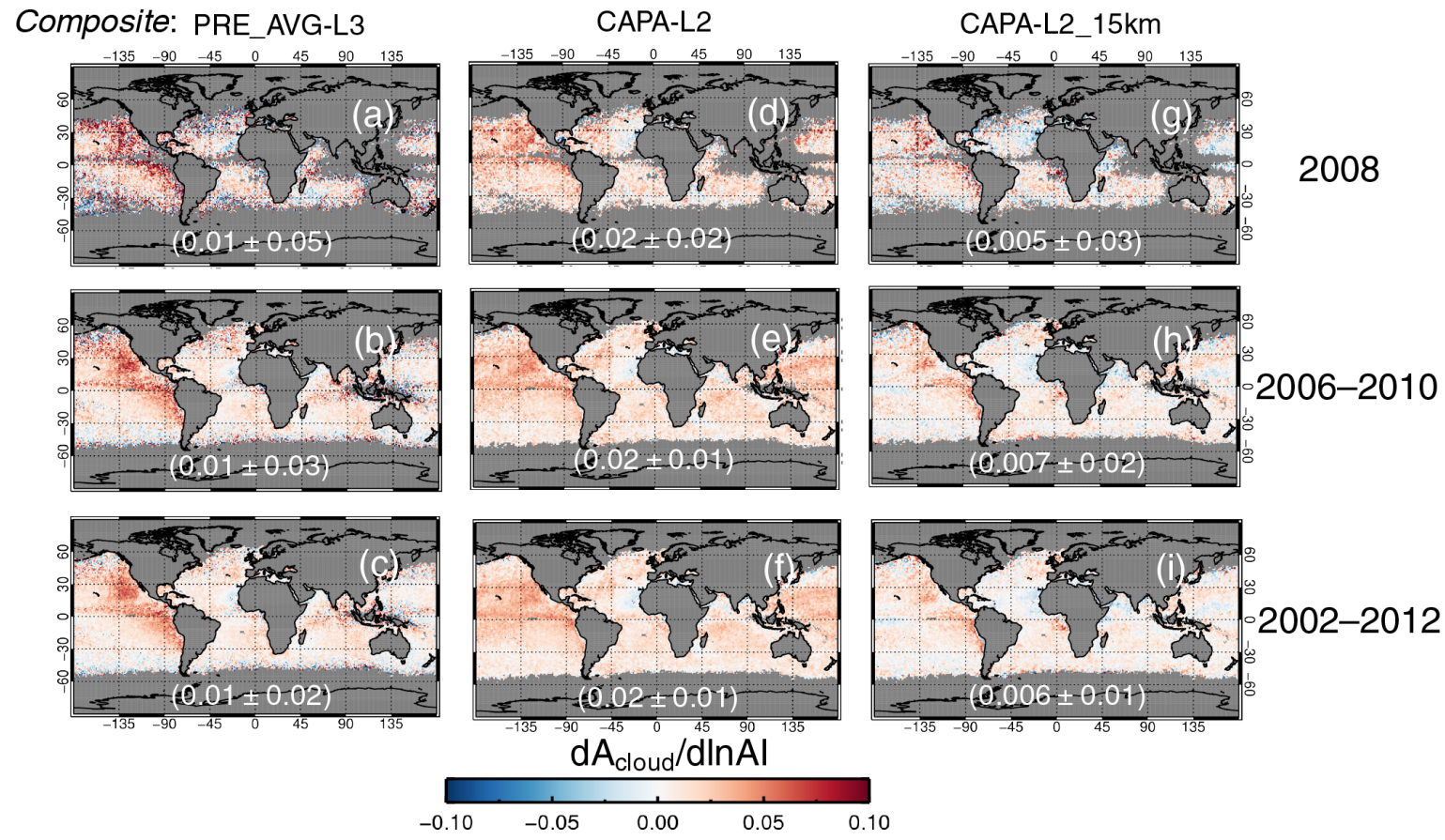

Figure 3. Cloud albedo sensitivity to changes in aerosol index averaged over $1^{\circ} \times 1^{\circ}$ regions using AATSR. Columns correspond to composites of the data based on the method selection in which the data are pre-averaged $(\mathbf{a}, \mathbf{b}, \mathbf{c})$ using level-3 daily gridded regions (left column; level 3), paired to the nearest high-resolution aerosol retrieval $(\mathbf{d}, \mathbf{e}, \mathbf{f})$ and paired to nearest high-resolution aerosol retrieval that is at least $15 \mathrm{~km}$ away from a cloud $(\mathbf{g}, \mathbf{h}, \mathbf{i})$. Paired observations are grouped into JJA periods using 1 year for 2008 (a, d, g), 5 years from 2006 to 2010, and 10 years from 2002 to 2012. Mean values and standard deviations of the spatial distribution are provided in parenthesis for each plot.

(a) PRE AVG-L3

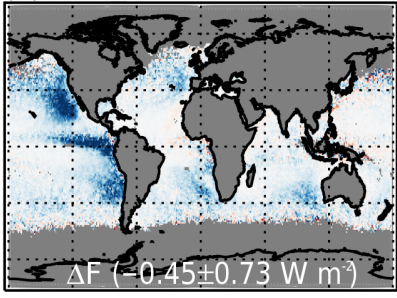

(b) CAPA-L2

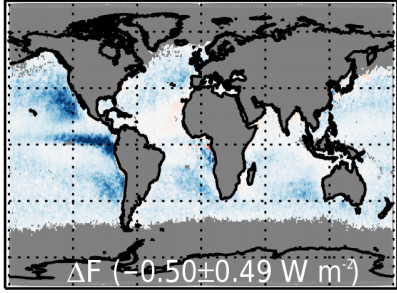

(c) CAPA-L2 $15 \mathrm{~km}$

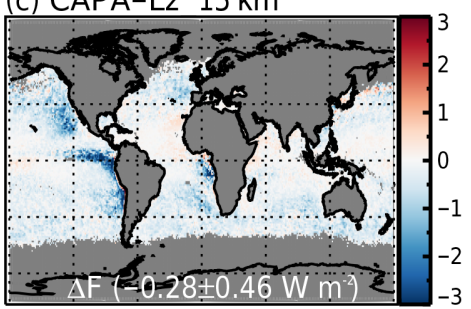

Figure 4. Intrinsic aerosol indirect radiative forcing computed using AATSR observations over oceanic $1^{\circ} \times 1^{\circ}$ regions during the period 2002-2012. Oceanic mean and standard deviation values are from the spatial distribution of the forcing $(\Delta F)$

larger values are observed in the Northern Hemisphere in accordance with the larger fractions of anthropogenic aerosol and maritime low-level clouds. Another, more notable, result displayed in Figs. 3 and 4 is the substantial decrease in the strength of the forcing when using the CAPA algorithm to screen for aerosols in the vicinity of clouds (i.e. between CAPA-L2_15km and the CAPA-L2 and PRE_AVG-L3 composites). The mean forcing estimate is smaller, partly because there are a larger fraction of grid boxes with negative cloud albedo sensitivities from just $11 \%$ (in CAPA-L2) to $31 \%$ (in CAPA-L2_15km). Because all three composites use the same cloud fraction and anthropogenic aerosol fraction climatologies, the radiative forcing differences are primarily due to the cloud albedo sensitivities as inferred from Eq. (4) and displayed in Fig. 3.

\subsection{Regression tests at regional scales}

To understand why the cloud albedo effect sensitivity is weaker when aerosols are removed close to clouds, we examine the diagnostics in several regions across the globe. Figure 5 shows the mean cloud albedo plotted as a function of the aerosol index for the California region. The linear regression slope between cloud albedo and AI is steeper when the clouds are paired to contaminated aerosols located within $15 \mathrm{~km}$ from another cloud. The cloud albedo also tends to 

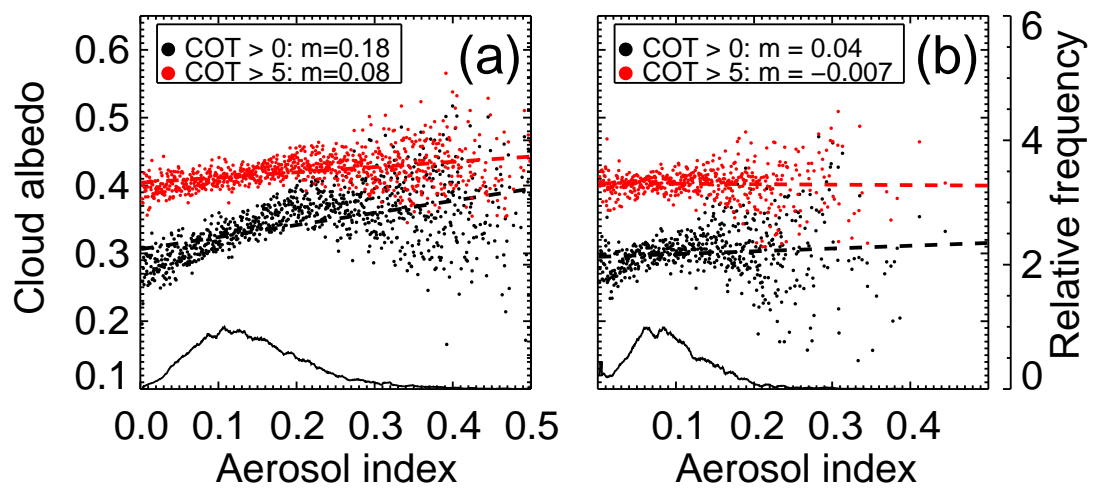

Figure 5. Binned cloud albedo as a function of aerosol index based on high-resolution aerosols that are paired to (a) the nearest cloud observation (CAPA-L2 method) and (b) the nearest cloud observation that is at least $15 \mathrm{~km}$ away (CAPA-L2_15km method) over JJA 2008 . Cases are binned by 0.001 -wide bins in $\mathrm{AI}$ over the California region $\left(20-30^{\circ} \mathrm{N}, 140-130^{\circ} \mathrm{W}\right)$. The relative frequency of occurrence in $\mathrm{AI}$ is also provided in the plot. Both methods are composited further by selecting cloud retrievals with cloud optical thickness (COT) greater than 5 (red points). Least squares fit line and value of the slope are provided for each composite.
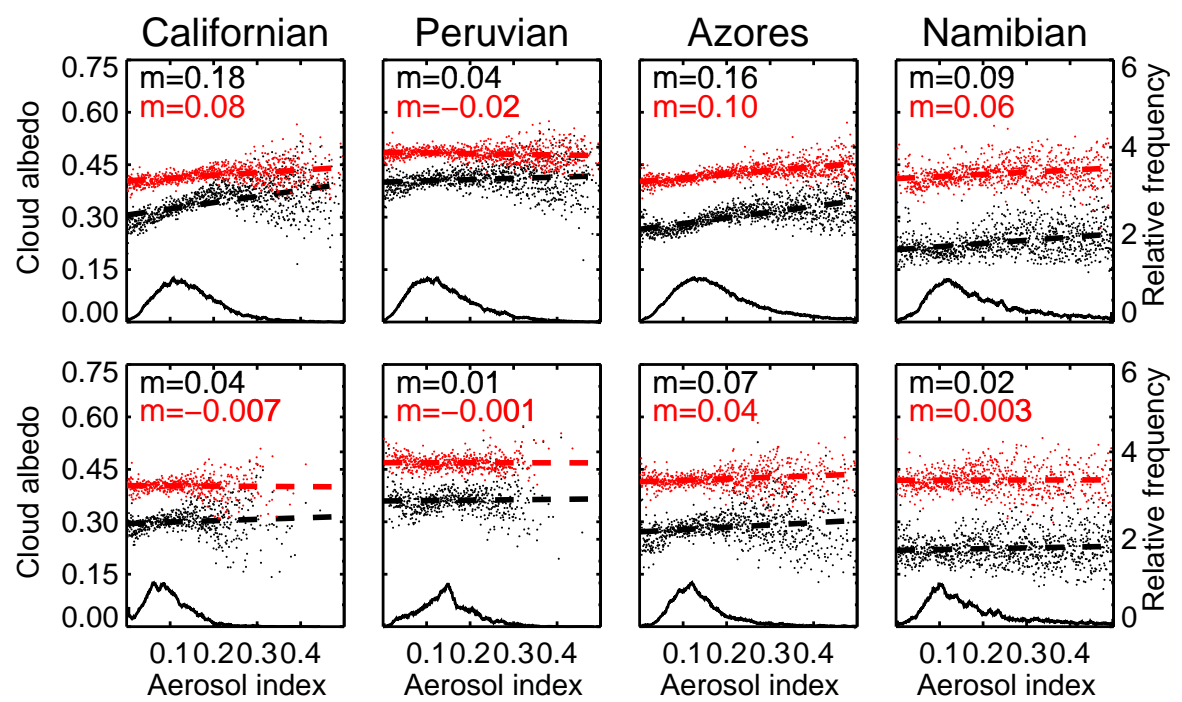

Figure 6. Same as Fig. 5 but for additional regions including Peru (10-20 $\left.\mathrm{S}, 80-90^{\circ} \mathrm{W}\right)$, the Azores $\left(15-25^{\circ} \mathrm{N}, 25-35^{\circ} \mathrm{W}\right)$, and Namibia $\left(10-20^{\circ} \mathrm{S}, 0-10^{\circ} \mathrm{E}\right)$.

increase monotonically as a function of AI until it reaches a value of about 0.25 in the CAPA-L2 composite. Beyond this value cloud albedo increases at a slower rate, because the clouds become less susceptible in a more polluted atmosphere. By contrast, when pairing the same clouds to aerosols that are located at least $15 \mathrm{~km}$ from another cloud the aerosol index values shift to smaller values and the slope between cloud albedo and AI decreases. Similar responses are also found in thicker clouds that are less "susceptible" (Platnick and Twomey, 1994) to aerosol perturbations (red points in Figs. 5 and 6) as well as in three other regions (Fig. 6). These results suggest that aerosols located in the vicinity of clouds may be more likely to contaminate and inflate the statistical relationships between cloud and aerosol properties.

\subsection{Aerosol-cloud radiative forcing estimates}

Intrinsic aerosol-cloud radiative forcing estimates are provided for each composite in Fig. 7. The estimates from AATSR and MODIS agree with each other and with the reported value from the MODIS Aqua and CERES afternoontrain observations in Chen et al. (2014) to within $0.1 \mathrm{~W} \mathrm{~m}^{-2}$. This relatively good agreement occurs despite the use of different temporal averaging periods. Furthermore, it is found that when no aerosol screening takes place in the preaveraged gridded (PRE_AVG-L3) and high-resolution cloudparing data sets (CAPA-L2) the forcing estimates are nearly two times larger than the composites that screen for aerosol near cloud. This is due to the weaker relationship between 


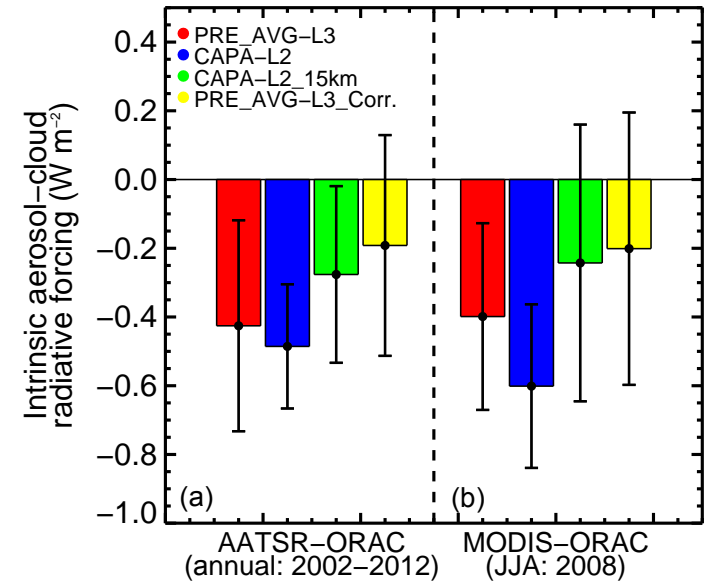

Figure 7. Estimated intrinsic aerosol-cloud radiative forcing by global marine warm clouds derived using top of atmosphere shortwave fluxes from AATSR-ORAC (a) and MODIS-ORAC (b). Estimates are provided using the pre-average standard level- 3 products (PRE_AVG-L3 composite; red), and pre-average corrected level-3 products in which the nearest aerosol is located at least $15 \mathrm{~km}$ from any other cloud (PRE_AVG-L3_Corr.; yellow), cloud pairs using the nearest high-resolution aerosol retrieval (CAPA-L2; blue) and cloud pairs using the nearest high-resolution aerosol retrieval that is at least $15 \mathrm{~km}$ away from any other cloud (CAPA-L2_15km; green). Error bars are calculated on the basis of the standard error of the regression slope.

cloud albedo and AI sensitivity for the aerosols selected farther away from clouds (CAPA-L2_15km).

Extrinsic aerosol-cloud radiative forcing estimates are shown in Figs. 8 and 9. In agreement with previous studies (e.g. Quaas et al., 2010; Chand et al., 2012; Grandey et al., 2013; Gryspeerdt et al., 2014) we find the $c_{\mathrm{f}}-\mathrm{AI}$ relationship is strongly positive in most locations, thereby producing a very strong radiative forcing (Fig. 8). However, this effect can be corrected. After reconstructing the pre-averaged aerosol data set based on screening out the aerosols close to clouds (PRE_AVG_Corr. composite), this process results in a decreased extrinsic aerosol indirect forcing estimate by approximately $70 \%$. This result agrees with the ground-based SURFRAD observations reported in Ten Hoeve and Augustine (2016) in which the removal of aerosols in the vicinity of clouds decreased the strength of the cloud fraction aerosol loading relationship. Furthermore, because cloud fraction covaries with relative humidity this estimate is still likely to be overestimated and could be further mitigated through the use of cloud droplet number concentration (Gryspeerdt et al., 2016).

Since numerous studies have used pre-averaged level-3type aerosol products we have tested whether these products can be corrected. Here, we have reconstructed the preaveraged aerosol product by removing near-cloud aerosols in the standard AATSR and MODIS data. The aerosol pixel

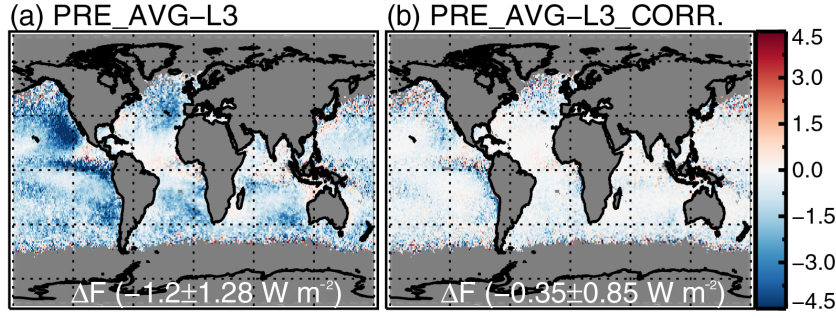

Figure 8. Extrinsic aerosol indirect radiative forcing computed using AATSR observations over oceanic $1^{\circ} \times 1^{\circ}$ regions during the period 2002-2012. Oceanic mean and standard deviation of the forcing $(\Delta F)$ are given in parenthesis.

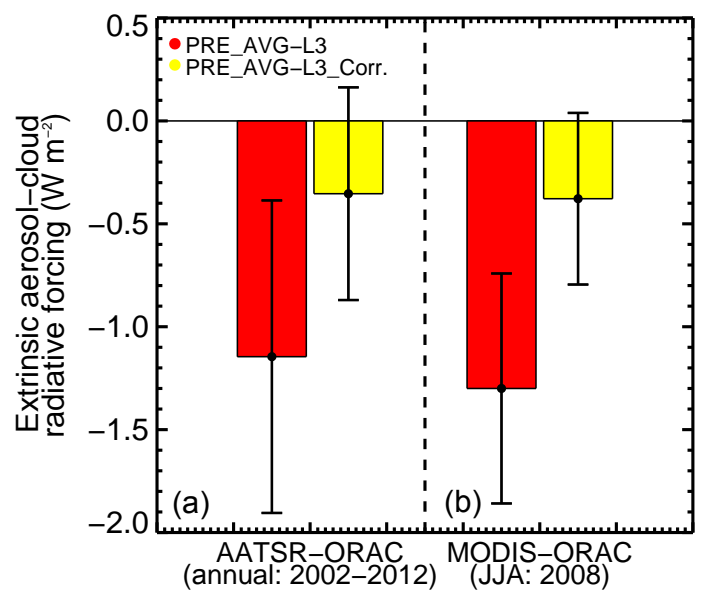

Figure 9. Estimated extrinsic aerosol-cloud radiative forcing by global marine warm clouds derived using top of atmosphere shortwave fluxes from AATSR-ORAC (a) and MODIS-ORAC (b). Estimates are provided using the pre-average standard level-3 products (PRE_AVG-L3 composite; red), and pre-average corrected level-3 products in which the nearest aerosol is located at least $15 \mathrm{~km}$ from any other cloud (PRE_AVG-L3_Corr.; yellow). Error bars are calculated on the basis of the standard error of the regression slope.

is removed if any part of the $10 \times 10 \mathrm{~km}^{2}$ area spanning the aerosol sample is located within $15 \mathrm{~km}$ from the nearest cloud. In general, similar forcing estimates are obtained when the cloud-contaminated aerosol is screened in the preaveraged $1^{\circ} \times 1^{\circ}$ products compared to the high-resolution aerosol-screened CAPA-L2_15km data.

On average the CAPA methods produce smaller 1- $\sigma$ standard error regression uncertainties (by up to $15 \%$ ) due to including a larger number of unique cloud-aerosol sampling pairs over each $1^{\circ}$ region. It is noteworthy that the actual number of degrees of freedom may be somewhat smaller, however, due to high spatial autocorrelation between sampled aerosol in each region as identified in many studies (e.g. Anderson et al., 2003; Schutgens et al., 2016; Kovacs, 2006; Santese et al., 2007; Shinozuka and Redemann, 2011). Nevertheless, the strength of the aerosol indirect forcing estimate 
Table 2. Aerosol-cloud radiative forcing estimated using Eq. (4) based on ORAC applied to AATSR over the 2002-2012 period and ORAC applied to MODIS collection 6 over JJA 2008 for low-level warm maritime clouds observed between $60^{\circ} \mathrm{S}$ and $60^{\circ} \mathrm{N}$. Retrievals are not used if they are identified over land or ocean regions with sea ice. Uncertainties are calculated on the basis of the propagated standard error of the regression slope through the radiative forcing calculation.

\begin{tabular}{|c|c|c|c|c|}
\hline & \multicolumn{2}{|c|}{ Intrinsic forcing $\left(\mathrm{W} \mathrm{m}^{-2}\right)$} & \multicolumn{2}{|c|}{ Extrinsic forcing $\left(\mathrm{W} \mathrm{m}^{-2}\right)$} \\
\hline $\begin{array}{l}\text { Nearest high-resolution cloud-aerosol pairs } \\
\text { (CAPA-L2) }\end{array}$ & $-0.49 \pm 0.18$ & $-0.60 \pm 0.24$ & $\mathrm{n} / \mathrm{a}$ & $\mathrm{n} / \mathrm{a}$ \\
\hline $\begin{array}{l}\text { Nearest high-resolution cloud-aerosol pairs } \\
\text { aerosol is at least } 15 \mathrm{~km} \text { from any cloud (CAPA-L2_15km) }\end{array}$ & $-0.28 \pm 0.26$ & $-0.24 \pm 0.40$ & $\mathrm{n} / \mathrm{a}$ & $\mathrm{n} / \mathrm{a}$ \\
\hline $\begin{array}{l}\text { Pre-averaged } 1^{\circ} \text { cloud and corrected aerosol pairs } \\
\text { pre-averaged aerosols are at least } 15 \mathrm{~km} \text { from clouds (PRE_AVG-L3_Corr.) }\end{array}$ & $-0.19 \pm 0.32$ & $-0.20 \pm 0.40$ & $-0.35 \pm 0.52$ & $-0.38 \pm 0.42$ \\
\hline
\end{tabular}

is similar between the corrected pre-averaged products and CAPA if strict screening of near-cloud aerosols is carried out first.

Overall, the intrinsic radiative forcing estimate of $-0.49 \pm$ $0.18 \mathrm{~W} \mathrm{~m}^{-2}$ agrees with the values reported in previous satellite-based studies (e.g. Sekiguchi et al., 2003; Quaas et al., 2008; Lebsock et al., 2008; Bellouin et al., 2013; Chen et al., 2014; Christensen et al., 2016a). However, when the aerosols are removed from the vicinity of clouds these methods produce radiative forcing estimates that are smaller by about $40 \%$, giving a new value of $-0.28 \pm 0.26 \mathrm{~W} \mathrm{~m}^{-2}$. In addition, the extrinsic forcing decreases by $70 \%$ (from $-0.60 \pm 0.24$ to $-0.24 \pm 0.40 \mathrm{~W} \mathrm{~m}^{-2}$ ), which is similar in strength to the radiative forcing metrics used to establish cloud fraction changes to increases in aerosol reported in Gryspeerdt et al. (2016). These results suggest that satellitebased estimates of the effective radiative forcing due to aerosol-cloud interactions represented in key climate reports (e.g. see the IPCC, 2013) may be exaggerated due to retrieval artefacts in the aerosol properties next to clouds. A summary of the estimates derived for oceanic regions are reported in Table 2.

\subsection{Uncertainty analysis}

We have assumed in this study that the aerosols are fairly homogenous across large spatial scales, up to $150 \mathrm{~km}$ according to the results presented in numerous studies examining the spatial autocorrelation length scale of aerosol optical thickness (e.g. Anderson et al., 2003; Schutgens et al., 2016; Kovacs, 2006; Santese et al., 2007; Shinozuka and Redemann, 2011). However, further analysis has been carried out here to address the spatial-scale dependence of the distance between the aerosol and cloud data. Using the observations from AATSR we run an additional test in which the aerosol is removed from nearby clouds up to a distance of
$30 \mathrm{~km}$ and then each cloud is paired to the nearest far-field aerosol pixel at this scale. Overall, the aerosol indirect forcing estimate is somewhat smaller in strength using $30 \mathrm{~km}$ scaling $\left(-0.20 \pm 0.26 \mathrm{~W} \mathrm{~m}^{-2}\right)$ compared to the scaling at $15 \mathrm{~km}\left(-0.28 \pm 0.27 \mathrm{~W} \mathrm{~m}^{-2}\right)$ but the differences between the composites are insignificant. Therefore, this suggests that the far-cloud aerosol statistics are representative of the same air mass as those found closer to clouds.

Besides the intrinsic/extrinsic radiative effect concept, we apply the CAPA data set to the aerosol indirect effect method developed in Quaas et al. (2008). The two methods have already been tested against each other and shown to agree very well for satellite observations in the North Atlantic (Amiri-Farahani et al., 2017). A fundamental difference between them is the additional susceptibility terms introduced by the Quaas et al. (2008) method. The first aerosol indirect effect can be written as $\left(\Delta F^{\mathrm{AIE}}=\overline{c_{m}} \cdot A\left(c_{m}, \tau_{c}\right) \frac{1}{3}\right.$. $\frac{d \ln N_{\mathrm{d}}}{\mathrm{d} \ln \mathrm{AI}} F^{\downarrow} \Delta \tau_{\mathrm{a}}^{\mathrm{MACC}}$, where the cloud droplet concentration, $N_{\mathrm{d}}$, is computed from cloud optical thickness and cloud droplet effective radius retrieval assuming an adiabatic approximation for clouds, $A\left(c_{m}, \tau_{c}\right)$ is given in the Appendix of Quaas et al. (2008), and $\tau_{c}$ is the cloud optical thickness). This term that includes the sensitivity of the planetary albedo (the planetary albedo is obtained from the fitting parameters used in Quaas et al., 2008) to a relative change in the cloud droplet number concentration and the sensitivity of cloud droplet number concentration to aerosol index $\left(\frac{d \ln N_{\mathrm{d}}}{\mathrm{d} \ln \mathrm{AI}}\right)$. The remainder term $\left(\Delta F^{\mathrm{AIE} 2}=\left[\left(\alpha-\left(a_{1}+a_{2} \ln \mathrm{AI}\right)\right)+\overline{c_{m}}\right.\right.$. $\left.A\left(c_{m}, \tau_{c}\right) \cdot\left(\frac{\mathrm{d} \ln c_{m}}{\mathrm{~d} \ln \mathrm{AI}}+\frac{\mathrm{d} \ln L}{\mathrm{~d} \ln \mathrm{AI}}\right)\right] F^{\downarrow} \Delta \tau_{\mathrm{a}}^{\mathrm{MACC}}$, where $a_{1}-a_{6}$ are the fitting parameters and $\alpha$ is the planetary albedo), may correspond to the cloud lifetime effect and includes log changes in both liquid water path $(L)$ and cloud fraction as a function of AI (where we have replaced the aerosol optical depth in the original formulation with $\mathrm{AI})$. In general, the total forcing estimate (i.e. adding the intrinsic and extrinsic 
terms together) tends to agree very well using the Quaas et al. (2008) approach (i.e. adding the first and second indirect effects together) but with the exception of the somewhat smaller PRE_AVG composite results. Using AATSRORAC data the PRE_AVG $\left(-1.1 \pm 0.8 \mathrm{~W} \mathrm{~m}^{-2}\right)$ and CAPAL2 $\left(-0.5 \pm 0.3 \mathrm{~W} \mathrm{~m}^{-2}\right)$ composites are significantly larger than the PRE_AVG_Corr. $\left(-0.49 \pm 0.75 \mathrm{~W} \mathrm{~m}^{-2}\right)$ and CAPAL2_15km $\left(-0.26 \pm 0.25 \mathrm{~W} \mathrm{~m}^{-2}\right)$ composites using the Quaas et al. (2008) statistical method. Furthermore, the first aerosol indirect forcing estimates for the PRE_AVG $(-0.14 \pm$ $\left.0.15 \mathrm{~W} \mathrm{~m}^{-2}\right)$ and CAPA-L2 $\left(-0.13 \pm 0.11 \mathrm{~W} \mathrm{~m}^{-2}\right)$ composites are also larger than the PRE_AVG_Corr. $(-0.09 \pm$ $\left.0.16 \mathrm{~W} \mathrm{~m}^{-2}\right)$ and CAPA-L2_15 $\mathrm{km}^{-}\left(-0.11 \pm 0.14 \mathrm{~W} \mathrm{~m}^{-2}\right)$ but these differences (across composites) are less pronounced compared to when the total forcing estimates are used. Nonetheless, these methods provide supporting evidence that aerosols located closer to clouds enhance the aerosol-cloud radiative effect.

\section{Conclusions}

Two independent satellite instruments, AATSR on Envisat and MODIS on Terra, were used in this study to test a new cloud-aerosol pairing algorithm to compute aerosol indirect forcing estimates for warm oceanic maritime clouds. Cloudaerosol pairs formed at the pixel-scale resolution of the satellite imager using CAPA can provide a larger sample size from which to compute correlation statistics between cloud albedo and aerosol index. The effect of the larger sample size effectively decreases the standard error of the regression slope, thereby providing higher confidence in the new radiative forcing estimates.

The scheme was also developed to determine the extent to which artefacts in aerosol retrievals located in the vicinity of clouds affect aerosol-cloud relationships in space-borne satellite observations. By removing aerosols located within $15 \mathrm{~km}$ of the nearest cloud, the cloud albedo effect (intrinsic) and cloud fraction effect (extrinsic) forcing decreased by 40 and $70 \%$, respectively. These new estimates suggest that aerosol effects on the radiative properties of clouds are even smaller than previously demonstrated from satellite-based studies. This new methodology therefore further widens the gap between the satellite and the very strong forcing estimates derived using most GCMs.

One inherent limitation to CAPA is it cannot be used to estimate the extrinsic (or overall) aerosol indirect forcing at the pixel-scale resolution of the satellite imager (typically at $1 \mathrm{~km})$. This is because the pairing algorithm uses pixels that are cloudy to do the pairing, thereby resulting in a grid-box mean cloud fraction value of 1.0. It is also generally not practical to use level-2 pixel-scale data in satellite-based assessments due to the large volume of data that are required at this scale. Therefore, we propose using CAPA (or another analogue) to remove the potentially contaminated aerosols within $15 \mathrm{~km}$ from nearby clouds as a first step to constructing pre-averaged level-3-type data sets. We demonstrate using 10 years of AATSR data that the broader-scale level-3 data can be corrected to yield the same intrinsic aerosolcloud sensitivities using the level-2 pixel scale, thereby providing a means to also compute the extrinsic aerosol indirect radiative forcing using the PRE_AVG broader-scale level-3 data.

This initial version of the CAPA algorithm has been used here to highlight a potential source of error in satellite-based estimates of aerosol indirect forcing. The CAPA method highlights areas where we have trust in the satellite-based retrievals that are pertinent for aerosol-cloud interactions. In subsequent versions of this algorithm additional steps could be pursued to increase computational efficiency. There are more efficient algorithms for finding nearest neighbours in a large data set. Binary search trees, such as a k-dimensional or vantage-point trees, would probably work very well within CAPA. Furthermore, this work would benefit from a deeper examination of the coupling between aerosol and cloud pairs using a back-trajectory model (such as the Hybrid Single Particle Lagrangian Integrated Trajectory) following the method described in Bréon et al. (2002).

Extension of this method in comparison with GCMs is explored in the companion paper of Neubauer et al. (2017). Furthermore, this companion paper also quantifies the impacts of meteorology on the aerosol-cloud relationships using numerous meteorological regimes based on lower-tropospheric stability and free-tropospheric relative humidity. These regimes are used for comparison with the global aerosol-climate model ECHAM6-HAM2. Also, the new CAPA diagnostics are used to select aerosols that are located far from clouds, thereby providing a more consistent comparison to the GCM which simulates interactions using dry-mode aerosols. The influence of dry-mode aerosols are also found to produce a much smaller indirect forcing estimate due to the dry aerosol being a better proxy for cloud condensation nuclei. These aspects are developed and explored further in Neubauer et al. (2017).

Code availability. Code to process aerosol, cloud, and broadband fluxes using ORAC can be obtained via https://github.com/ ORAC-CC/ORAC (ORAC, 2017).

Data availability. The Centre for Environmental Data Analysis (CEDA; http://www.ceda.ac.uk, ESA, 2014) provided the AATSR satellite data. NASA Goddard (https://ladsweb.nascom.nasa.gov) provided the MODIS satellite data used in this paper. 
Author contributions. MC developed the CAPA algorithm and applied it to the satellite data sets for the analysis in this paper. DN had the original idea for and helped in the design of the CAPA algorithm. CP produced the AATSR-ORAC cloud products, GT produced the AATSR-ORAC aerosol products. GM, AP, SP and DG provided support needed to run ORAC. MC wrote the paper with comments from all co-authors.

Competing interests. The authors declare that they have no conflict of interest

Acknowledgements. We would like to thank our international members of the ORAC team at Deutscher Wetterdienst, for all of the support in running the retrieval algorithm. We would also like to thank Johannes Quaas for providing the planetary albedo data. CEDA provided the computational infrastructure of JASMIN-CEMS needed to process this data. This research was completed as part of ERACE (The Environmental Response to Aerosols Observed in CCI ECVs), being a programme of, and funded by, the European Space Agency through a Living Planet Fellowship and the Cloud_cci (contract: 4000109870/13/I-NB) and the Aerosol_cci projects (ESA Contract No. 4000109874/14/I-NB). This study was also funded as part of NERC's support of the National Centre for Earth Observation.

Edited by: Armin Sorooshian

Reviewed by: three anonymous referees

\section{References}

Albrecht, B. A.: Aerosols, cloud microphysics, and fractional cloudiness, Science, 245, 1227-1230, https://doi.org/10.1126/science.245.4923.1227, 1989.

Amiri-Farahani, A., Allen, R. J., Neubauer, D., and Lohmann, U.: Impact of Saharan dust on North Atlantic marine stratocumulus clouds: importance of the semidirect effect, Atmos. Chem. Phys., 17, 6305-6322, https://doi.org/10.5194/acp-176305-2017, 2017.

Anderson, T. L., Charlson, R. J., Winker, D. M., Ogren, J. A., and Holmén, K.: Mesoscale Variations of Tropospheric Aerosols, J. Atmos. Sci., 60, 119-136, https://doi.org/10.1175/15200469(2003)060<0119:MVOTA>2.0.CO;2, 2003.

Bellouin, N., Quaas, J., Morcrette, J.-J., and Boucher, O.: Estimates of aerosol radiative forcing from the MACC re-analysis, Atmos. Chem. Phys., 13, 2045-2062, https://doi.org/10.5194/acp13-2045-2013, 2013.

Benedetti, A., Morcrette, J.-J., Boucher, O., Dethof, A., Engelen, R. J., Fisher, M., Flentje, H., Huneeus, N., Jones, L., Kaiser, J. W., Kinne, S., Mangold, A., Razinger, M., Simmons, A. J., and Suttie, M.: Aerosol analysis and forecast in the European Centre for Medium-Range Weather Forecasts Integrated Forecast System: 2. Data assimilation, J. Geophys. Res., 114, D13205, https://doi.org/10.1029/2008JD011115, 2009.

Bréon, F.-M., Tanré, D., and Generoso, S.: Aerosol Effect on Cloud Droplet Size Monitored from Satellite, Science, 295, 834-838, https://doi.org/10.1126/science.1066434, 2002.
Chand, D., Wood, R., Ghan, S. J., Wang, M., Ovchinnikov, M., Rasch, P. J., Miller, S., Schichtel, B., and Moore, T.: Aerosol optical depth increase in partly cloudy conditions, J. Geophys. Res., 117, D17207, https://doi.org/10.1029/2012JD017894, 2012.

Chen, Y.-C., Christensen, M. W., Stephens, G. L., and Seinfeld, J. H.: Satellite-based estimate of global aerosol-cloud radiative forcing by marine warm clouds, Nat. Geosci., 7, 643-646, https://doi.org/10.1038/ngeo2214, 2014.

Christensen, M. W., Chen, Y.-C., and Stephens, G. L.: Aerosol indirect effect dictated by liquid clouds, J. Geophys. Res., 121, 14636-14650, https://doi.org/10.1002/2016JD025245, 2016 a.

Christensen, M. W., Poulsen, C., McGarragh, G., and Grainger, R. G.: Algorithm Theoretical Basis Document (ATBD) of the Community Code for CLimate (CC4CL) Broadband Radiative Flux Retrieval (CC4CL-TOAFLUX) module, ESA Cloud CCI, 1, available at: http://www.esa-cloud-cci.org (last access: 20 October 2017), 2016b.

ESA (European Space Agency): AATSR Multimission land and sea surface data, version 2.1. NERC Earth Observation Data Centre, available at: http://catalogue.ceda.ac.uk/uuid/ 1d0c047ea3ced97cc7e988d7d286052a (last access: 20 October 2017), 2014.

Feingold, G., McComiskey, A., Yamaguchi, T., Johnson, J. S., Carslaw, K. S., and Schmidt, K. S.: New approaches to quantifying aerosol influence on the cloud radiative effect, Proc. Natl. Acad. Sci. USA, 113, 5812-5819, https://doi.org/10.1073/pnas.1514035112, 2016.

Grandey, B. S. and Stier, P.: A critical look at spatial scale choices in satellite-based aerosol indirect effect studies, Atmos. Chem. Phys., 10, 11459-11470, https://doi.org/10.5194/acp-10-114592010, 2010.

Grandey, B. S., Stier, P., and Wagner, T. M.: Investigating relationships between aerosol optical depth and cloud fraction using satellite, aerosol reanalysis and general circulation model data, Atmos. Chem. Phys., 13, 3177-3184, https://doi.org/10.5194/acp-13-3177-2013, 2013.

Gryspeerdt, E., Stier, P., and Grandey, B. S.: Cloud fraction mediates the aerosol optical depth-cloud top height relationship, J. Geophys. Res. Lett., 41, 3622-3627, https://doi.org/10.1002/2014GL059524, 2014.

Gryspeerdt, E., Stier, P., White, B. A., and Kipling, Z.: Wet scavenging limits the detection of aerosol effects on precipitation, Atmos. Chem. Phys., 15, 7557-7570, https://doi.org/10.5194/acp15-7557-2015, 2015.

Gryspeerdt, E., Quaas, J., and Bellouin, N.: Constraining the aerosol influence on cloud fraction, J. Geophys. Res., 121, 3566-3583, https://doi.org/10.1002/2015JD023744, 2016.

Gryspeerdt, E., Quaas, J., Ferrachat, S., Gettelman, A., Ghan, S., Lohmann, U., Morrison, H., Neubauer, D., Partridge, D. G., Stier, P., Takemura, T., Wang, H., Wang, M., and Zhang, K.: Constraining the instantaneous aerosol influence on cloud albedo, Proc. Natl. Acad. Sci. USA, 114, 4899-4904, https://doi.org/10.1073/pnas.1617765114, 2017.

Henderson, D. S., L'Ecuyer, T., Stephens, G., Partain, P., and Sekiguchi, M.: A Multisensor Perspective on the Radiative Impacts of Clouds and Aerosols, J. Appl. Meteorol. Clim., 52, 853871, https://doi.org/10.1175/JAMC-D-12-025.1, 2013. 
Hollmann, R.: ESA Cloud cci Product Validation and Intercomparison Report (PVIR), ESA Cloud cci, 4, available at: http: //www.esa-cloud-cci.org, last access: 20 October 2017.

IPCC: Summary for policymakers, in: Climate Change 2013: The Physical Science Basis, Contribution of Working Group I to the Fifth Assessment Report of the Intergovernmental Panel on Climate Change, edited by: Stocker, T. F., Qin, D., and Plattner, G., Cambridge University Press, Cambridge, United Kingdom and New York, NY, USA, 2013.

Kovacs, T.: Comparing MODIS and AERONET aerosol optical depth at varying separation distances to assess ground-based validation strategies for spaceborne lidar, J. Geophys. Res.-Atmos., 111, D24203, https://doi.org/10.1029/2006JD007349, 2006.

Lebsock, M. D., Stephens, G. L., and Kummerow, C.: Multisensor satellite observations of aerosol effects on warm clouds, J. Geophys. Res., 113, D15205, https://doi.org/10.1029/2008JD009876, 2008.

Levy, R. C., Mattoo, S., Munchak, L. A., Remer, L. A., Sayer, A. M., Patadia, F., and Hsu, N. C.: The Collection 6 MODIS aerosol products over land and ocean, Atmos. Meas. Tech., 6, 29893034, https://doi.org/10.5194/amt-6-2989-2013, 2013.

McGarragh, G., Poulsen, C., G. Thomas, A. P., Sus, O., Schlundt, C., Stapelberg, S., Proud, S., Christensen, M., Stengel, M., and Grainger, R.: The Community Cloud Retrieval for Climate (CC4CL). Part II: The optimal estimation approach, Atmos. Meas. Tech. Discuss., submitted, 2017.

Morcrette, J.-J., Boucher, O., Jones, L., Salmond, D., Bechtold, P., Beljaars, A., Benedetti, A., Bonet, A., Kaiser, J. W., Razinger, M., Schulz, M., Serrar, S., Simmons, A. J., Sofiev, M., Suttie, M., Tompkins, A. M., and Untch, A.: Aerosol analysis and forecast in the European Centre for Medium-Range Weather Forecasts Integrated Forecast System: Forward modeling, J. Geophys. Res., 114, D06206, https://doi.org/10.1029/2008JD011235, 2009.

Nakajima, T., Higurashi, A., Kawamoto, K., and Penner, J. E.: A possible correlation between satellite-derived cloud and aerosol microphysical parameters, J. Geophys. Res. Lett., 28, 11711174, https://doi.org/10.1029/2000GL012186, 2001.

Neubauer, D., Christensen, M. W., Poulsen, C. A., and Lohmann, U.: Unveiling aerosol-cloud interactions - Part 2: Minimising the effects of aerosol swelling and wet scavenging in ECHAM6-HAM2 for comparison to satellite data, 17, 1316513185, https://doi.org/10.5194/acp-17-13165-2017, 2017.

ORAC (Department of Physics, University of Oxford, Clarendon Laboratory, Parks Road, Oxford, UK RAL Space - Rutherford Appleton Laboratory, Chilton, Didcot, UK DWD - Deutscher Wetterdienst, Offenbach, Germany): ORAC code, available at: https://github.com/ORAC-CC/ORAC, last access: 1 November 2017.

Platnick, S. and Twomey, S.: Determining the Susceptibility of Cloud Albedo to Changes in Droplet Concentration with the Advanced Very High Resolution Radiometer, J. Appl. Meteorol., 33, 334-347, https://doi.org/10.1175/15200450(1994)033<0334:DTSOCA>2.0.CO;2, 1994.

Platnick, S., Meyer, K. G., King, M. D., Wind, G., Amarasinghe, N., Marchant, B., Arnold, G. T., Zhang, Z., Hubanks, P. A., Holz, R. E., Yang, P., Ridgway, W. L., and Riedi, J.: The MODIS Cloud Optical and Microphysical Products: Collection 6 Updates and Examples From Terra and Aqua, IEEE T. Geosci. Remote. Sens., 55, 502-525, https://doi.org/10.1109/TGRS.2016.2610522, 2017.

Poulsen, C. A., Siddans, R., Thomas, G. E., Sayer, A. M., Grainger, R. G., Campmany, E., Dean, S. M., Arnold, C., and Watts, P D.: Cloud retrievals from satellite data using optimal estimation: evaluation and application to ATSR, Atmos. Meas. Tech., 5, 1889-1910, https://doi.org/10.5194/amt-5-1889-2012, 2012.

Quaas, J., Boucher, O., Bellouin, N., and Kinne, S.: Satellite-based estimate of the direct and indirect aerosol climate forcing, J. Geophys. Res., 113, D05204, https://doi.org/10.1029/2007JD008962, 2008.

Quaas, J., Stevens, B., Stier, P., and Lohmann, U.: Interpreting the cloud cover - aerosol optical depth relationship found in satellite data using a general circulation model, Atmos. Chem. Phys., 10, 6129-6135, https://doi.org/10.5194/acp-10-6129-2010, 2010.

Remer, L. A., Kaufman, Y. J., Tanré, D., Mattoo, S., Chu, D. A., Martins, J. V., Li, R.-R., Ichoku, C., Levy, R. C., Kleidman, R. G., Eck, T. F., Vermote, E., and Holben, B. N.: The MODIS Aerosol Algorithm, Products, and Validation, J. Atmos. Sci., 62, 947-973, https://doi.org/10.1175/JAS3385.1, 2005.

Santese, M., De Tomasi, F., and Perrone, M. R.: Moderate Resolution Imaging Spectroradiometer (MODIS) and Aerosol Robotic Network (AERONET) retrievals during dust outbreaks over the Mediterranean, J. Geophys. Res.-Atmos., 112, D18201, https://doi.org/10.1029/2007JD008482, 2007.

Schutgens, N. A. J., Gryspeerdt, E., Weigum, N., Tsyro, S., Goto, D., Schulz, M., and Stier, P.: Will a perfect model agree with perfect observations? The impact of spatial sampling, Atmos. Chem. Phys., 16, 6335-6353, https://doi.org/10.5194/acp-166335-2016, 2016.

Sekiguchi, M., Nakajima, T., Suzuki, K., Kawamoto, K., Higurashi, A., Rosenfeld, D., Sano, I., and Mukai, S.: A study of the direct and indirect effects of aerosols using global satellite data sets of aerosol and cloud parameters, J. Geophys. Res., 108, 4699, https://doi.org/10.1029/2002JD003359, 2003.

Shinozuka, Y. and Redemann, J.: Horizontal variability of aerosol optical depth observed during the ARCTAS airborne experiment, Atmos. Chem. Phys., 11, 8489-8495, https://doi.org/10.5194/acp-11-8489-2011, 2011.

Stephens, G., Li, J., Wild, M., Clayson, C., Loeb, N., Kato, S., L'Ecuyer, T., Stackhouse, P., Lebsock, M., and Andrews, T.: An update on Earth's energy balance in light of the latest global observations, Nat. Geosci., 5, 691-696, https://doi.org/10.1038/NGEO1580, 2012.

Stephens, G. L., Gabriel, P. M., and Partain, P. T.: Parameterization of Atmospheric Radiative Transfer. Part I: Validity of Simple Models, J. Atmos. Sci., 58, 3391-3409, https://doi.org/10.1175/15200469(2001)058<3391:POARTP>2.0.CO;2, 2001.

Stevens, B. and Feingold, G.: Untangling aerosol effects on clouds and precipitation in a buffered system, Nature, 461, 607-613, https://doi.org/10.1038/nature08281, 2009.

Sus, O., Jerg, M., Poulsen, C., Thomas, G., Stapelberg, S., Mcgarragh, G., Povey, A., Schlundt, C., Stengel, M., and Hollmann. R.: The Community Cloud Retrieval for Climate (CC4CL). Part I: A framework applied to multiple satellite imaging sensors., Atmos. Meas. Tech. Discuss., submitted, 2017.

Ten Hoeve, J. E. and Augustine, J. A.: Aerosol effects on cloud cover as evidenced by ground-based and space-based observa- 
tions at five rural sites in the United States, J. Geophys. Res. Lett., 43, 793-801, https://doi.org/10.1002/2015GL066873, 2016.

Thomas, G. E., Carboni, E., Sayer, A. M., Poulsen, A., Siddans, R., and Grainger, R. G.: Satellite Aerosol Remote Sensing over Land: Oxford-RAL Aerosol and Cloud (ORAC): aerosol retrievals from satellite radiometers edited by: Kokhanovsky, A. A. and de Leeuw, G., Springer Berlin Heidelberg, 2009.

Twohy, C. H., Coakley, J. A., and Tahnk, W. R.: Effect of changes in relative humidity on aerosol scattering near clouds, J. Geophys. Res., 114, D05205, https://doi.org/10.1029/2008JD010991, 2009.

Twomey, S.: Pollution and the planetary albedo, Atmos. Environ., 8, 1251-1256, https://doi.org/10.1016/0004-6981(74)90004-3, 1974.
Varnái, T. and Marshak, A.: MODIS observations of enhanced clear sky reflectance near clouds, J. Geophys. Res. Lett., 36, L06807, https://doi.org/10.1029/2008GL037089, 2009.

Várnai, T. and Marshak, A.: Analysis of co-located MODIS and CALIPSO observations near clouds, Atmos. Meas. Tech., 5, 389-396, https://doi.org/10.5194/amt-5-389-2012, 2012.

Várnai, T. and Marshak, A.: Effect of Cloud Fraction on NearCloud Aerosol Behavior in the MODIS Atmospheric Correction Ocean Color Product, Remote Sens., 7, 5283-5299, https://doi.org/10.3390/rs70505283, 2015.

Várnai, T., Marshak, A., and Yang, W.: Multi-satellite aerosol observations in the vicinity of clouds, Atmos. Chem. Phys., 13, 38993908, https://doi.org/10.5194/acp-13-3899-2013, 2013. 